\title{
Study of the Mode I and Mode II interlaminar behaviour of a carbon fabric reinforced thermoplastic
}

\author{
I. De Baere, S. Jacques, W. Van Paepegem and J. Degrieck \\ Department of Materials Science and Engineering, Faculty of Engineering and Architecture, \\ Ghent University. Technologiepark-Zwijnaarde 903, B-9052 Zwijnaarde, Belgium. \\ E-mail: Ives.DeBaere@UGent.be
}

\begin{abstract}
A delamination or an interlaminar failure is a critical failure mechanism for fibrereinforced composites and, therefore, has already been studied extensively by many researchers. However, it remains an actual research topic, since every day, new polymers with better mechanical properties are being developed for fibre reinforced composites.

This manuscript describes an experimental study of both the Mode I and Mode II interlaminar behaviour of a 5-harness satin weave carbon fabric reinforced polyphenylene sulphide (PPS). The mode I crack growth is studied using the Double Cantilever Beam (DCB) setup, whereas the mode II behaviour was studied by the End Notch Flexure (ENF) test. For mode I, an unstable crack-growth was seen resulting in a saw-tooth like force-displacement curve. Therefore, a model based on Linear Elastic Fracture Mechanics was considered to determine $\mathrm{G}_{\mathrm{IC}}$ for both initiation and propagation. Furthermore, the effect of possible fibre-bridging was assessed and an online microscopic study was conducted so that the origin of the specific jumps in crack growth could be determined. For mode II, stable crack propagation occurred and the Compliance-Based Beam Method was used to determine $\mathrm{G}_{\text {IIC }}$ for both initiation and propagation.

It could be concluded that the considered approach worked well for this material and reproducible results and values were found.
\end{abstract}

\section{Introduction and Principle}

The interlaminar failure of composites is a well known problem. As such, there are already a lot of studies dedicated to the interlaminar behaviour of fibre reinforced polymers, as illustrated in various literature reviews [1, 2, 3, 4]. In most cases, unidirectional reinforcement is considered, quite often in combination with epoxymatrices. With respect to the crack growth, Mode I is mostly studied and preferred over Mode II.

However, not that many studies have already been performed on both the Mode I and Mode II crack propagation for a fabric reinforced thermoplastic, as is the subject of the underlying manuscript. In a study by Fracasso et al. [5], the emphasis was on the effect of temperature and strain rate on the values of the Mode I and Mode II fracture toughness.

Zenasni et al. [6, 7] have performed a similar study as described here. They also considered a carbon fabric reinforced thermoplastic, namely PEI, but the reinforcement was 8-harness satin weave. Furthermore, their emphasis was more on comparing different theories for the determination of $\mathrm{G}_{\text {IC }}$ and $\mathrm{G}_{\text {IIC }}$ and not so much on the crack behaviour, as is the case in the current study. Finally, they only consider crack initiation 
from the insert, not the crack propagation in the material. For [7], they considered the influence of moisture.

In this manuscript, the emphasis lies on the crack propagation of a fabric reinforced thermoplastic. The Mode I behaviour was investigated with the commonly used Double Cantilever Beam setup, but since the force-displacement curve deviated from the expected form, as discussed in the 'ASTM D5520-01 Standard test method for Mode I interlaminar fracture toughness of unidirectional fiber-reinforced polymer matrix composites' the proposed characteristic points, such as the point of non-linearity, the $5 \%$ deviation of the linear behaviour or the maximum force, do not seem a correct option for the determination of $\mathrm{G}_{\mathrm{IC}}$. As such, the value for the Mode I fracture toughness is derived by fitting a model based on Linear Elastic Fracture Mechanics on the experimental results. Furthermore, a microscopic evaluation of the side of the specimen was conducted to investigate the specific jumps during crack growth.

The mode II crack growth was investigated using the End Notch Flexure setup, since this proved an interesting setup with little effect of friction and little scatter on the value of $\mathrm{G}_{\text {IIC }}$ [8]. The three-point bending setup is chosen over the four-point version, to allow for microscopic evaluation of the sides. The latter is not possible for the four-point method with our microscopic setup, as the indenting roles prevent correct placement of the microscope. By doing a displacement-controlled test and fulfilling a geometrical demand, stable crack propagation should be achieved [9].

The material considered for this research is a carbon fibre 5-harness satin weave reinforced polyphenylene sulphide (PPS), of which there is 3 tons in every Airbus A380, making it an important material in aeronautical applications. To the authors' best knowledge, the interlaminar behaviour of this material has not yet been published.

The next paragraph illustrates the used material and methods, after which both the DCB and ENF experiments are discussed. Finally, some conclusions are drawn.

\section{Materials and Methods}

\subsection{Composite Material}

The material under study was a carbon fibre-reinforced polyphenylene sulphide (PPS), called CETEX. This material is supplied to us by Ten Cate. The fibre type is the carbon fibre T300J $3 \mathrm{~K}$ and the weaving pattern is a 5-harness satin weave with a mass per surface unit of $286 \mathrm{~g} / \mathrm{m}^{2}$. The 5-harness satin weave (Figure 1) is a fabric with high strength in both directions and excellent bending properties.

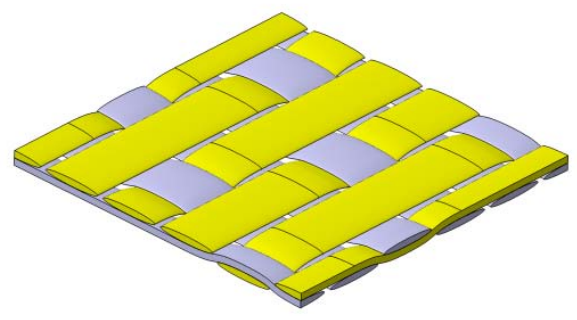

Figure 1 Illustration of the 5-harness satin weave pattern.

The carbon PPS plates were hot pressed at 10 bars and $310{ }^{\circ} \mathrm{C}$; only one stacking sequence was used for this study, namely a $\left[\left(0^{\circ}, 90^{\circ}\right)_{4},\left(90^{\circ}, 0^{\circ}\right)_{4}\right]_{\mathrm{s}}$ where $\left(0^{\circ}, 90^{\circ}\right)$ represents one layer of fabric. By using this stacking sequence, the crack can propagate 
between two layers oriented in the warp or $0^{\circ}$ direction. The delamination is manufactured by inserting a Kapton layer of $13 \mu \mathrm{m}$ thick between the two middle layers before hot pressing. Because of the high processing temperature, Teflon was not an option.

The in-plane elastic properties of the individual carbon PPS lamina were determined by the dynamic modulus identification method as described in [10] and are listed in Table 1.

Table 1 In-plane elastic properties of the individual carbon/PPS lamina (dynamic modulus identification method).

\begin{tabular}{lcr}
\hline$E_{11}$ & 56.0 & $\mathrm{GPa}$ \\
$\mathrm{E}_{22}$ & 57.0 & $\mathrm{GPa}$ \\
$\nu_{12}$ & 0.033 & - \\
$\mathrm{G}_{12}$ & 4.175 & $\mathrm{GPa}$ \\
\hline
\end{tabular}

The tensile strength properties of the lamina were determined at the Technical University of Delft and are listed in Table 2.

Table 2 Tensile strength properties of the individual carbon/PPS lamina (Mechanical testing at TUDelft).

\begin{tabular}{lcc}
\hline $\mathrm{X}_{\mathrm{T}}$ & 734.0 & $\mathrm{MPa}$ \\
$\varepsilon_{11}{ }^{\text {ult }}$ & 0.011 & - \\
$\mathrm{Y}_{\mathrm{T}}$ & 754.0 & $\mathrm{MPa}$ \\
$\varepsilon_{22}{ }{ }^{\mathrm{ult}}$ & 0.013 & - \\
$\mathrm{S}_{\mathrm{T}}$ & 110.0 & $\mathrm{MPa}$ \\
\hline
\end{tabular}

The test coupons were sawn with a water-cooled diamond saw. Figure 2 shows the dimensions of the Double Cantilever Beam specimens and Figure 3 shows the used End Notch Flexure geometry.

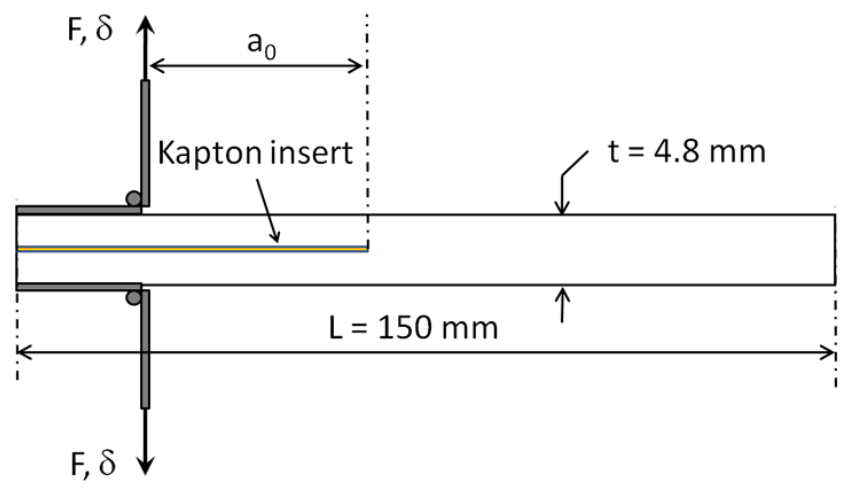

Figure 2 Dimensions of the used Double Cantilever Beam specimen. 


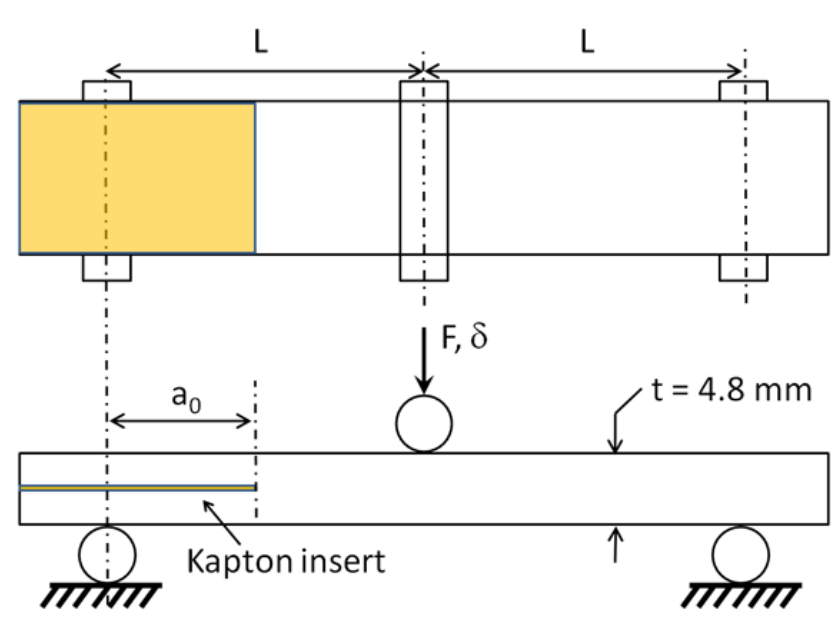

Figure 3 Dimensions of the used End Notch Flexure specimen

\subsection{Equipment}

All tensile tests were performed on an electromechanical INSTRON 5800R tensile testing machine with a FastTrack 8800 digital controller and a load cell of $\pm 10 \mathrm{kN}$. The quasi-static tests were displacement-controlled.

For the registration of the tensile data, a combination of a National Instruments USB 6251 data acquisition card and the SCB-68 pin shielded connector were used. The load $\mathrm{F}$ and displacement $\delta$, given by the FastTrack controller were sampled on the same time basis.

\section{Experiments and Discussion}

\subsection{Mode I Double Cantilever Beam experiments}

Preliminary tests have shown that the stable crack propagation which usually occurs for unidirectional reinforcement, is not present, but a saw-tooth like force-displacement curve manifests itself, due to the fact that the reinforcement is a fabric. As such, the methodology for determining the value of $\mathrm{G}_{\mathrm{IC}}$ given by the 'ASTM D5528-01 Standard test method for Mode I interlaminar fracture toughness of unidirectional fiberreinforced polymer matrix composites' cannot be used. Moreover, upon first loading of the specimen, the kapton insert tended to stick a little to both adherends, most likely due to the high processing temperatures. This, however, caused deviations from the expected linear slope before crack growth, making it impossible to determine the actual point of crack initiation. As it proved very difficult to open the specimen in such a way that the kapton had released entirely, but without causing any crack growth so that the normal behaviour was found upon a second opening, it was decided to immediately induce a pre-crack, which would also simulate more realistic circumstances. Indeed, in real life applications, there will not be an insert (and corresponding stress concentration around the tip) present to induce a man made delamination, so cracks will initiate and propagate from damage locations due to load history. The pre-crack is induced by opening the specimen at $2 \mathrm{~mm} / \mathrm{min}$ on the tensile machine until the first crack jump occurs. Next, the specimen is unloaded and the actual crack length, including the precrack, is measured using a microscope. Then, the actual test is conducted.

Table 3 gives the dimensions of the specimens considered here.

Table 3 Dimensions of the used DCB-specimens

Specimen Width $\quad \mathrm{a}_{0}$ before pre-crack $\quad \mathrm{a}_{0}$ after pre-crack




\begin{tabular}{lccc}
\hline & {$[\mathrm{mm}]$} & {$[\mathrm{mm}]$} & {$[\mathrm{mm}]$} \\
CET1 & 22.5 & 48.3 & 52.0 \\
CET2 & 22.5 & 48.3 & 52.7 \\
CET3 & 22.8 & 48.3 & 52.6 \\
CET4 & 22.5 & 47.8 & 55.1 \\
\hline
\end{tabular}

Figure 4 shows the force-displacement curves for all experiments described in this manuscript. For a first type of experiments, the crosshead was moved at a constant speed of $2 \mathrm{~mm} / \mathrm{min}$. The results of these tests are shown for three specimens (CET1, CET2 and CET4) in Figure 4 and the unstable saw tooth-like crack propagation can clearly be seen. It should be noted that such a behaviour was not mentioned in [6] for the 8-harness weave, but they did not consider crack propagation, so they might not have come across this phenomenon. In [7], this behaviour can be seen in the forcedisplacement curves, but only very limited. They are still able to use the characteristic points in the ASTM standard (NL, 5\% and $\mathrm{P}_{\max }$ ). Such stick slipping was also reported in [5] for a fabric reinforced PEEK and in [11] for a UD composite, but for the latter, the effect was due to the low temperature, influencing the PEEK matrix. Furthermore, it may be noted that despite the unstable growth, the reproducibility is quite high, both for these experiments and others, not shown here. The initial bending stiffness of specimen CET2 is higher than for the other specimens, which is in fact unexpected, since the initial delamination length of CET2 is slightly higher than the others (see Table 3). However, when observing the images taken of the side just after the pre-crack (Figure 5), it can be seen that for example for CET1, the crack tip is not in the centre of the specimen, contrary to CET2. As such, there is one adherent thinner than the other for CET1, resulting in a lower bending stiffness (and of course similar for the other specimens). This was verified using the finite element software Abaqus ${ }^{\mathrm{TM}}$ and indeed, significant variations in opening stiffness occur when the crack position is varied in the vicinity of the centre of the DCB specimen. The effect of of the length of the pre-crack can be seen when comparing CET4 with CET1 and CET3; the pre-crack is roughly $2.5 \mathrm{~mm}$ longer for CET4, the stiffness is significantly little lower. 


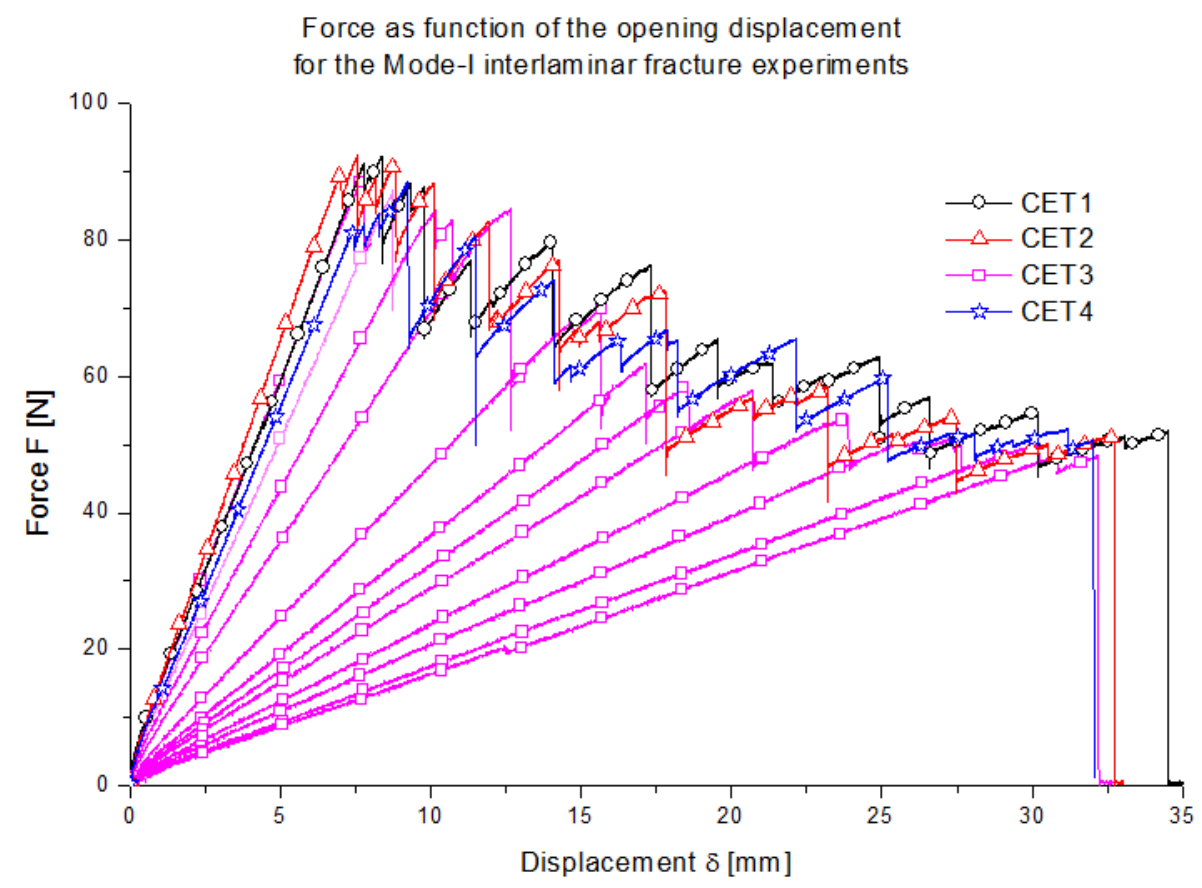

Figure 4 Force-displacement curve for the DCB tests on all specimens mentioned in this manuscript.

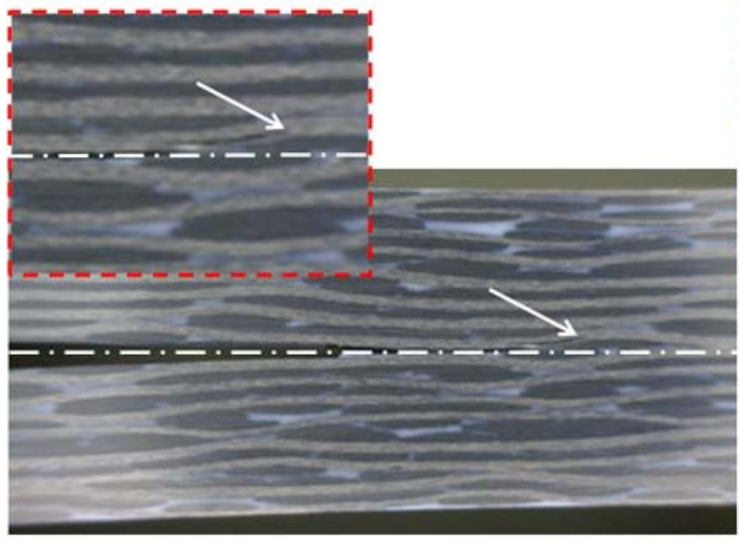

(a) pre-crack of CET1

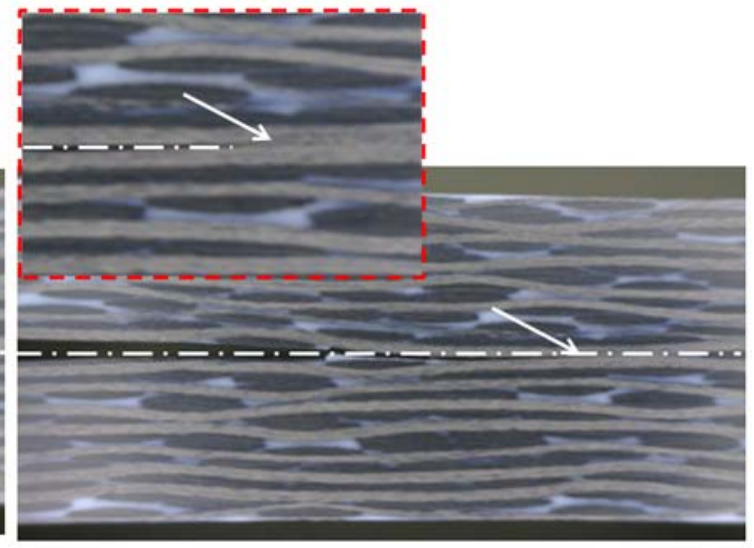

(b) pre-crack of CET2

Figure 5 Illustration of the crack tip after inducing a pre-crack in the specimens.

For a second type of experiments, the specimen was again loaded at $2 \mathrm{~mm} / \mathrm{min}$ until the crack propagated, after which it was unloaded, to verify whether this had any influence. The idea is to evaluate the effect of fibre-bridging. By closing the specimen after each loading, any fibres bridging the crack are most likely crushed or buckled, hence eliminating the reinforcing by bridging. The results of such a test (specimen CET3) are shown in Figure 6, the unloading of the specimen after each crack jump is not shown for clarity. It should again be noted that similar results were confirmed for other specimens tested this way. 


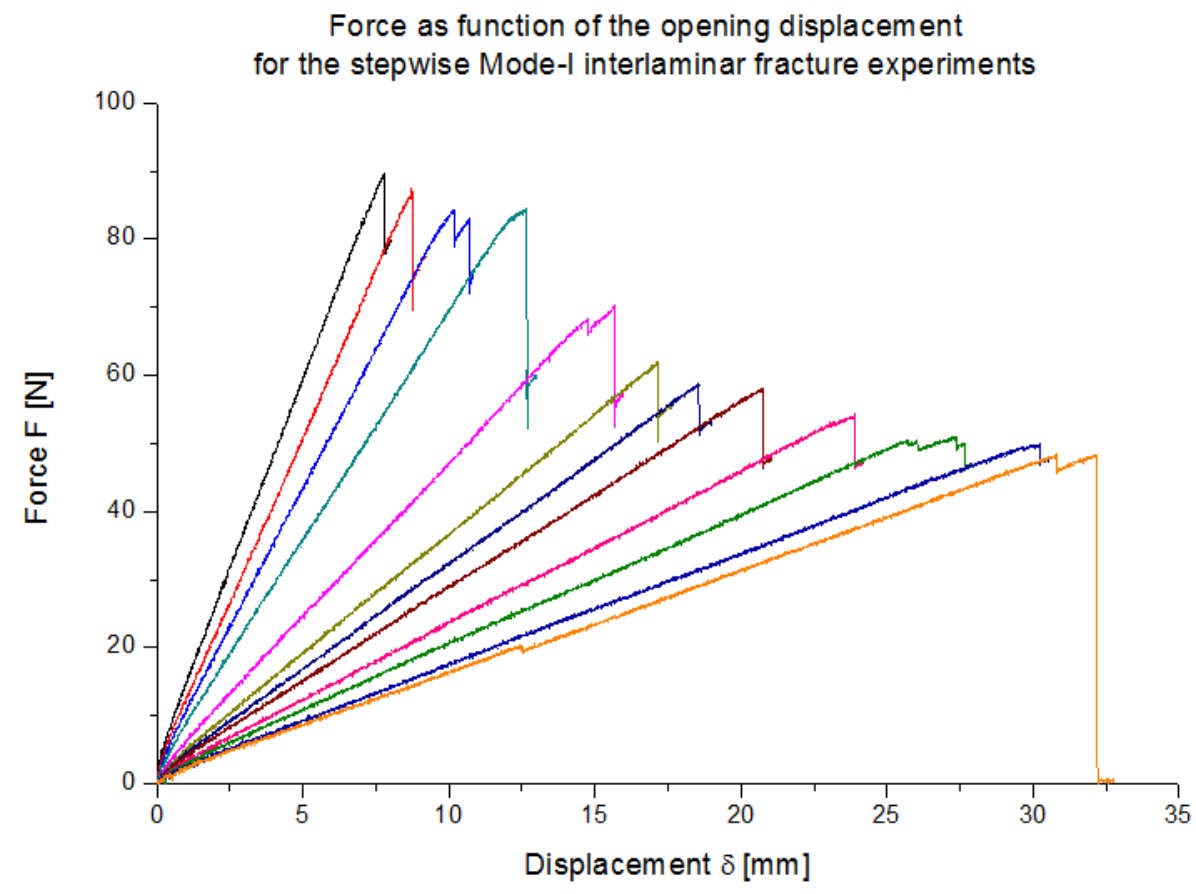

Figure 6 Force-displacement curve for the stepwise DCB tests on CET3

As the envelope of this curve is very similar to the curves of CET1, CET2 and CET4, both in shape and in values, the effect of fibre-bridging cannot clearly be visualised just by looking at the force-displacement curves, so further analysis is necessary.

In order to determine the value of $\mathrm{G}_{\mathrm{I}}$, an analytical model based on linear elastic fracture mechanics is used. The necessary force $\mathrm{F}$ for crack propagation is given by [12]:

$$
\mathrm{F}=\sqrt{\frac{G_{I C} b^{2} h^{3} E_{11}}{12 a^{2}}}
$$

With $\quad \mathrm{G}_{\mathrm{IC}}$ the critical strain energy release rate $[\mathrm{N} / \mathrm{m}]$

$\mathrm{b}$ the width of the specimen [mm]

$\mathrm{h}$ half the thickness of the specimen [mm]

$\mathrm{E}_{11}$ Young's modulus in the warp direction $[\mathrm{Pa}]$

a the length of the delamination [mm]

The corresponding displacement $\delta$ is given by [12]:

$$
\delta=F \frac{8 a^{3}}{b h^{3} E_{11}}
$$

Eliminating the delamination length a from both equations yields:

$$
F=\sqrt{8}\left(\frac{G_{I C}}{12}\right)^{\frac{3}{4}} \frac{1}{\sqrt{\delta}} b\left(h^{3} E_{11}\right)^{\frac{1}{4}}=f\left(G_{I C}\right) \delta^{-0.5}
$$

The general idea is to fit Equation 3 on the experimentally derived curves in order to have a value for $\mathrm{G}_{\mathrm{IC}}$, since all other parameters in Equation 3 are known. However, the choice remains on what part of the curve it should be fitted. Since $\mathrm{G}_{\mathrm{IC}}$ corresponds with crack growth, it is logical to fit it on the top peaks of each curve, corresponding with the point at which the crack is about to propagate. Figure 7 shows the best fitting power 
laws on three of the mentioned experiments, without taking the exponent of -0.5 into account. It can be seen that the exponent is close but not equal to -0.5.

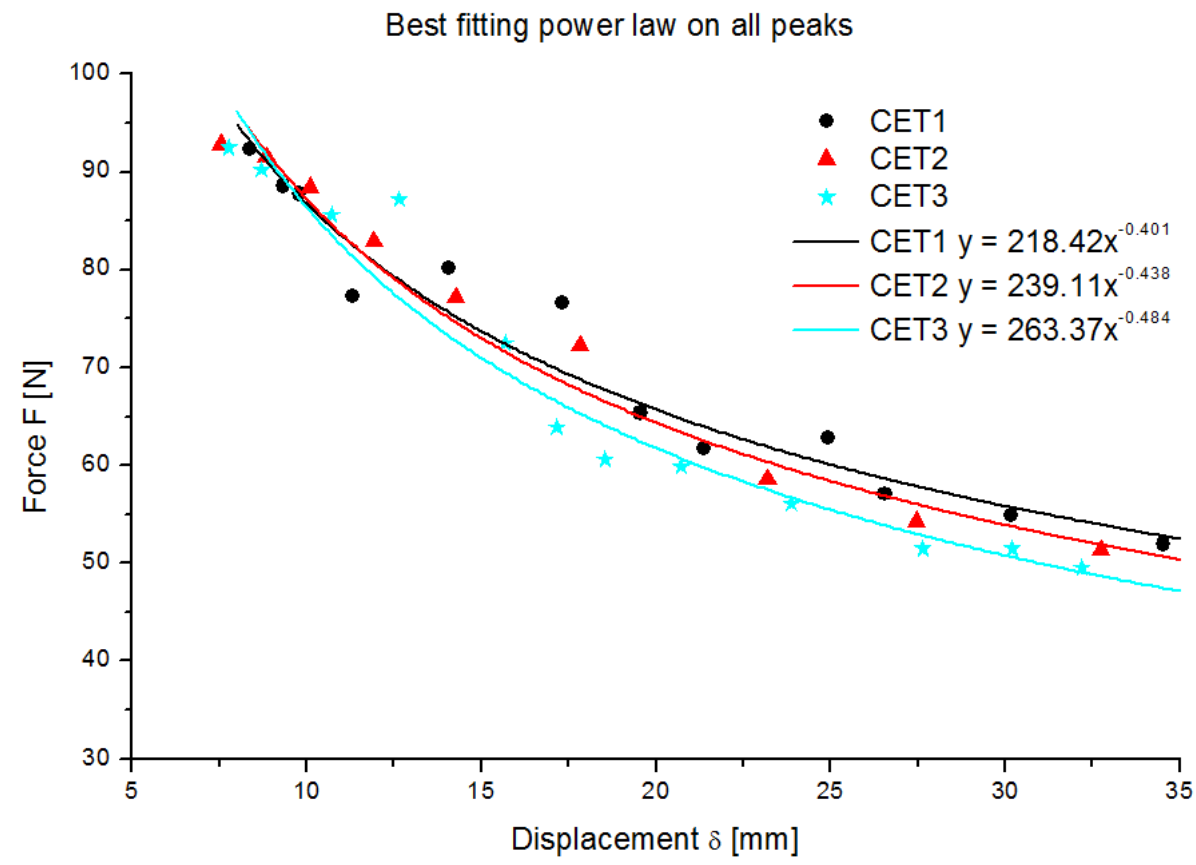

Figure 7 Illustration of the best fitting power laws on the peaks just before crack propagation

As such, there are two options. The first is fitting Equation 3 through the very first peak, since this is the initiation of the crack. This will yield a value for $\mathrm{G}_{\mathrm{IC} \text {,initiation and is }}$ illustrated in Figure 8. It can be seen that these curves do not capture the behaviour after initiation well, with exception of CET3. For a given $\delta$, the force is always underestimated.

It should also be noted that for higher opening values, the peak force for CET3 is always lower than for the two other specimens, confirming the assumption that closing the specimen after each crack jump, eliminates at least partially the effect of fibrebridging. 


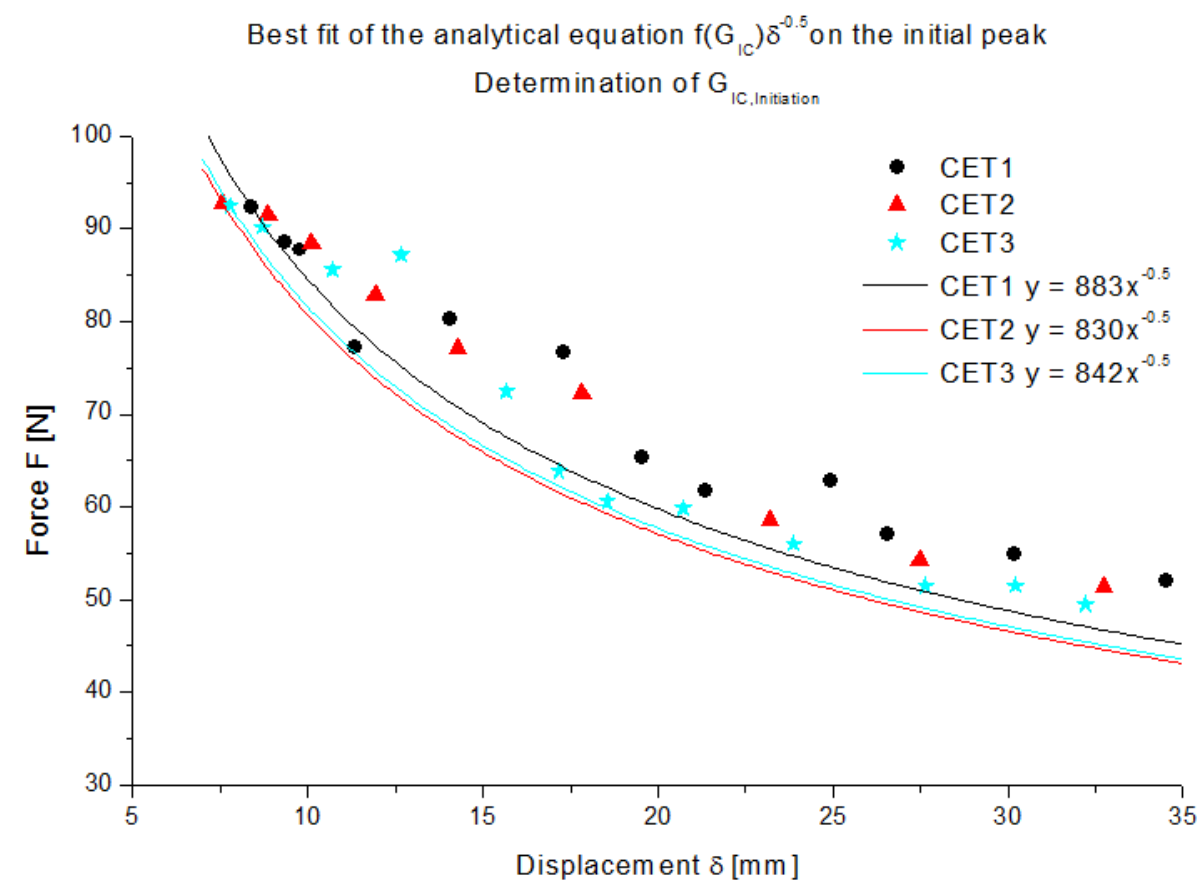

Figure 8 Illustration of the best fit of Equation 3 on the first peak just before crack propagation

Because of the consequently underestimation of the peak forces, a second option is considered, namely fitting Equation 3 through all peaks, except the first. This will yield

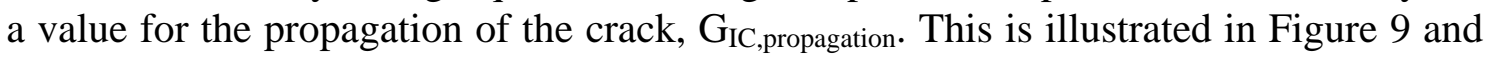
yields a better approximation for the curves, but it overestimates the force for initiation, meaning the first peak of every curve.

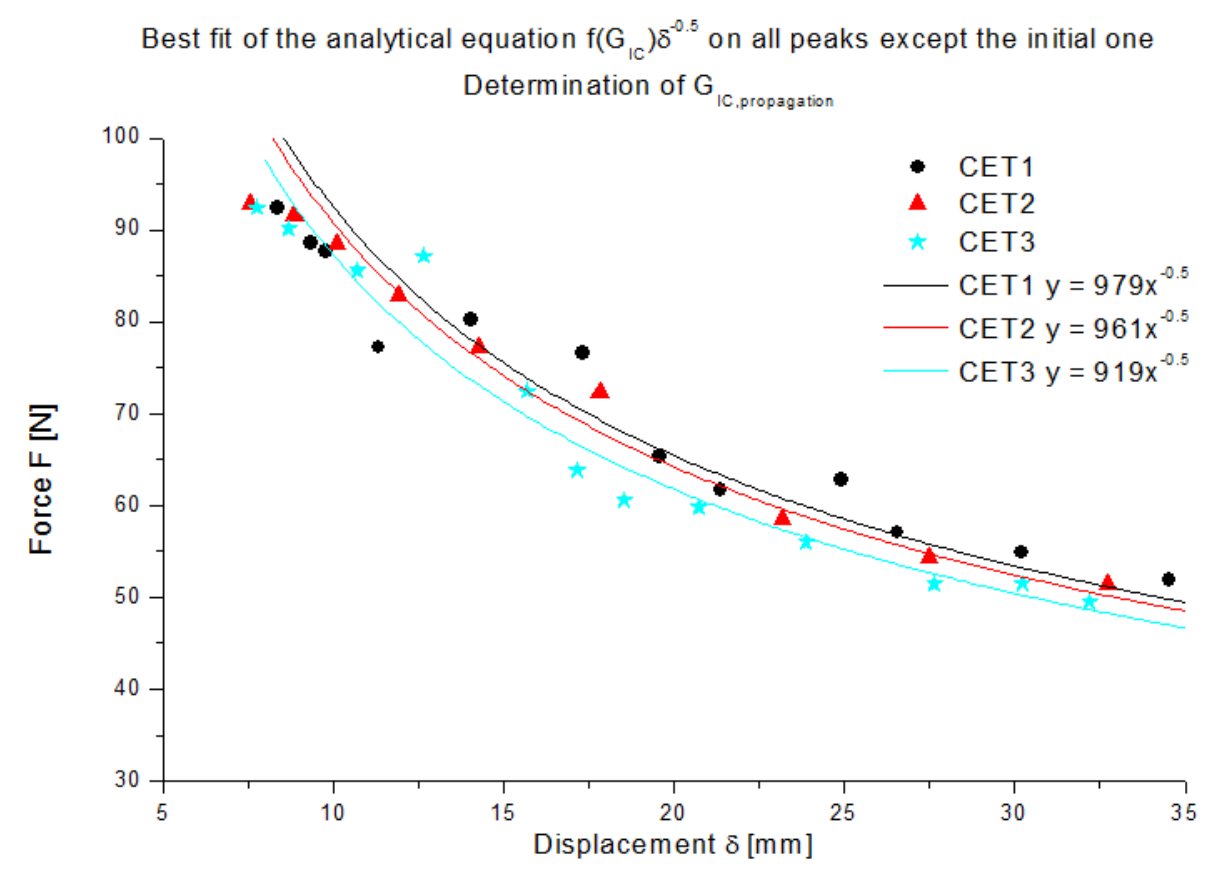

Figure 9 Illustration of the best fit of Equation 3 on all of the peaks just before crack propagation

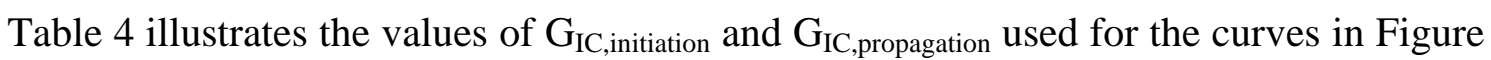
8 and Figure 9. From these values it can be clearly seen that the energy needed for a crack to initiate is lower than for propagation. This is most likely due to the fact that more fibre-bridging occurs during propagation than during initiation. Since the 
experiment started from a pre-crack, rather than from the insert, it is not impossible that there is already some fibre-bridging present for the initiation.

Comparing these values to literature, higher values of around $4000 \mathrm{~J} / \mathrm{m}^{2}$ were found for the 8-harness PEI [6,7], but this is most likely due to difference in matrix (PEI versus PPS) and weave pattern.

Table 4 Overview of the derived values for $\mathrm{G}_{\mathrm{IC}}$

\begin{tabular}{ccc}
\hline Specimen & $\mathrm{G}_{\mathrm{IC} \text {,initiation }}\left[\mathrm{J} / \mathrm{m}^{2}\right]$ & $\mathrm{G}_{\mathrm{IC} \text {,propagation }}\left[\mathrm{J} / \mathrm{m}^{2}\right]$ \\
CET1 & 883 & 979 \\
CET2 & 830 & 961 \\
CET3 & 842 & 919 \\
\hline
\end{tabular}

To further investigate the origin of the saw tooth like force-displacement curve and to assess the role of the fabric in this part and to validate the above mentioned values of $\mathrm{G}_{\mathrm{IC}}$, another specimen, CET4 was tested. Prior to testing, one side was polished and crack growth was monitored during the experiment using a travelling microscope. Pictures were taken every time the crack propagated, so that the crack jump can be visualised by comparing the successive pictures. It was verified that there was no stable crack propagation in between two teeth of the saw-tooth like force-displacement curve, so the picture just after one crack jump is still relevant to compare with the next jump with respect to the crack tip position.

Figure 10 illustrates the load-displacement curve of the experiment, which is of course similar to that of CET1 and CET2; in total 17 pictures were taken, corresponding with the numbers on the force-displacement curve. Furthermore, the analytical prediction (Equation 3) is also plotted for the averaged values of both $\mathrm{G}_{\mathrm{IC} \text {,initiation }}$ and $\mathrm{G}_{\mathrm{IC} \text {,propagation }}$ to validate these values. As can be seen, both curves capture the behaviour quite nice. The

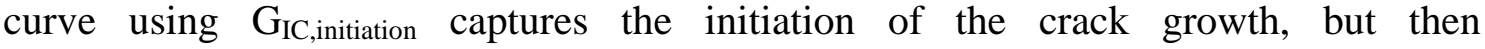
underestimates the peak forces, whereas the curve using $\mathrm{G}_{\mathrm{IC} \text {,propagation }}$ overestimates crack initiation, but predicts the propagation peaks very well.

Force as function of the opening displacement corresponding with the visual study of the Mode-I interlaminar fracture experiment

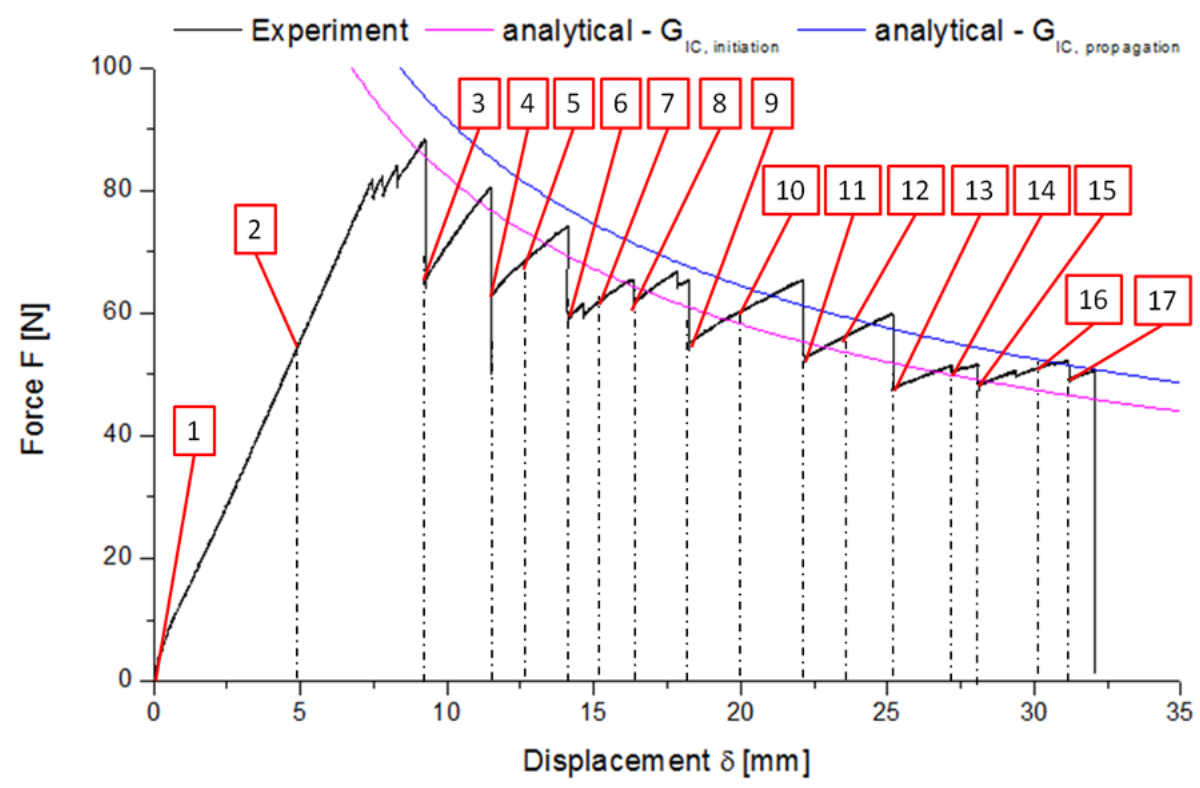

Figure 10 Force-displacement curve for the DCB test on CET4, used for the visual study of the crack growth 
In general, the following remarks can be made (also see Figure 11):

- The crack tip after a jump is either just before or just after two contacting weft $\left(90^{\circ}\right)$ fibre bundles.

- The propagation length on the polished edge is not constant. However, the following scenario's, seen from the polished edge, occur:

1. The crack propagated along an entire unit cell, about $7.4 \mathrm{~mm}$. The crack can start either before a weft bundle, or after a weft bundle, depending on the previous jump (Figure 11 (a)). This happened at jumps 3-4, and 12-13 (Figure 10)

2. The crack propagates from just after one weft bundle till just before the next, meaning it grows between the warp bundles (Figure 11 (b)). This occurred at 56 and 16-17.

3. The crack propagates along a single weft bundle (Figure 11(c)), which happened at 8-9 and 14-15.

- Occasionally, meta-delaminations also occur, meaning that a crack travels in the fabric just above the symmetry-plane (Figure 11(d)). This occurred at 7-8 and 1011.

- Rarely, the crack propagated very little (less than $0.05 \mathrm{~mm}$ )in between two warp bundles, which could be seen at 6-7, 13-14 and 15-16, where a very small decrease in force was present.

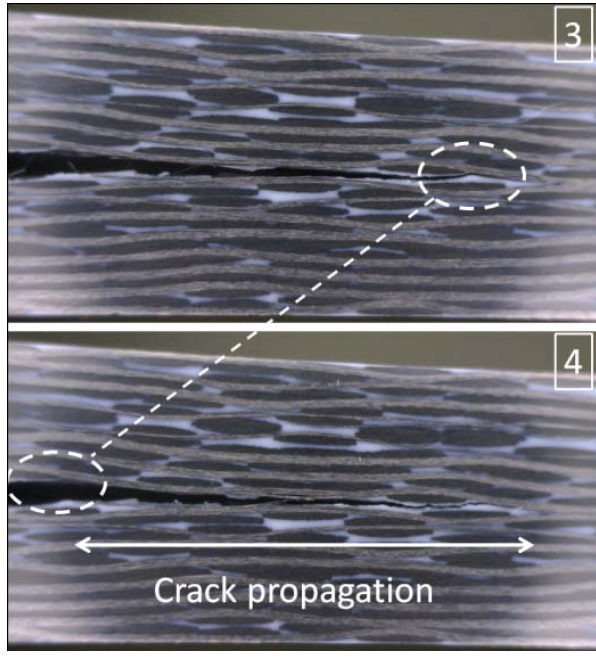

(a) full unit-cell jump
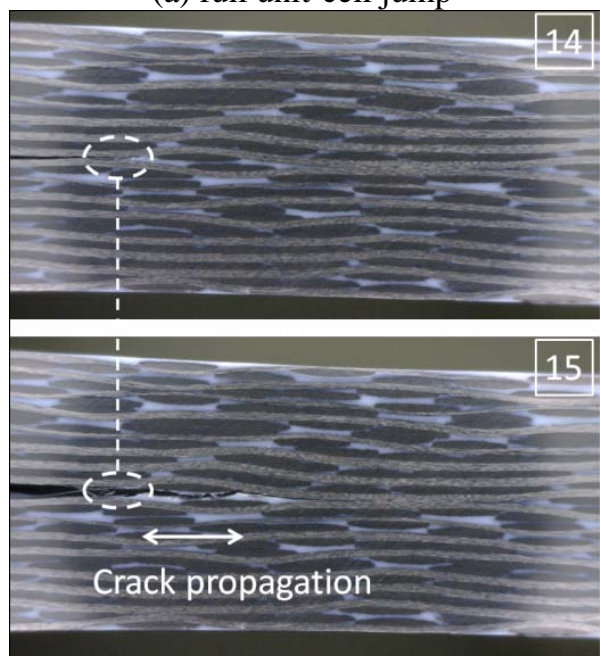
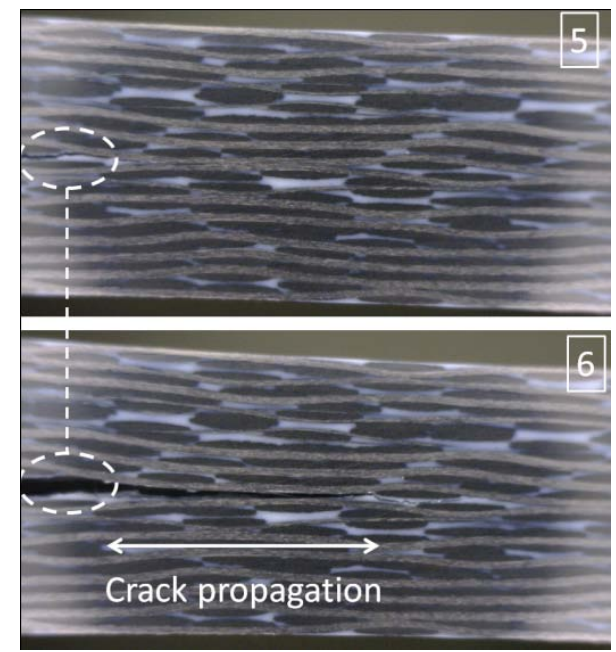

(b) jump between weft bundles
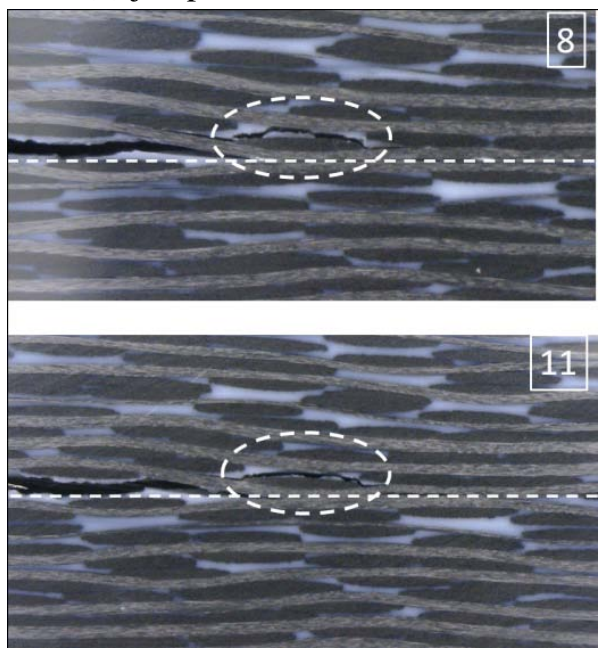
Figure 11 Overview of the occurring types of crack growth (specimen CET4)

It was observed that the crack does not show a stable propagation between the warp $\left(0^{\circ}\right)$ bundles, although in some cases a small crack was present, resulting from a previous jump. This, however, can be explained by the fact that the weave is a 5-harness, meaning that the local geometry seen on the edge is not the same throughout the width of the specimen (see Figure 1), the crossing-over point of weft and warp shifts in the pattern.

Since events 1, 2 and 3 happen at random, it is clear that the crack does not always travel the same distance. Moreover, it is very likely that the value of the fracture toughness depends on the exact position of the crack tip, explaining the scatter on the results in Table 4.

Coming back to Table 4, there is still one issue which needs to be clarified. Usually, it is

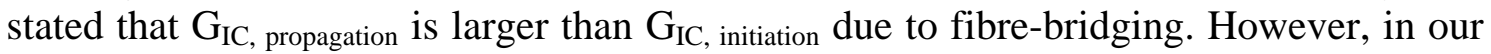
experiments, a pre-crack was always introduced to avoid the stress concentration from the insert. As such, some fibre-bridging should already occur. The authors assume that indeed fibre-bridging is present during crack propagation, but by closing the entire specimen, the bridging fibres fail due to buckling or crushing. As such, upon next opening (e.g. after the pre-crack or for the entire test on specimen CET3) no fibrebridging is present. This also explains the constant lower peak values for CET3 compared to CET1 and CET2 in Figure 7.

Finally, it should be noted that the crack front was visualised with an ultrasonic C-scan during an experiment similar to CET3, were the specimen was examined after each unloading. It was verified that the front remained a straight line, perpendicular to the length of the specimen.

\section{2. $\quad$ Mode II End Notch Flexure experiments}

The $\mathrm{G}_{\text {IIC }}$ can be obtained from the End Notch Flexural test (ENF), meaning simple three-point bending experiments on specimens with an initial delamination, as already illustrated in Figure 3. The determination of $\mathrm{G}_{\text {IIC }}$ is done according to the 'ComplianceBased Beam Method', as explained in [9, 13]. This method has two important advantages: (i) there is no need to continuously measure the delamination length during the experiment and (ii) this method takes the material degradation just behind the crack tip into account. This method only has one demand with respect to the geometry, namely that $\mathrm{a}_{0} / \mathrm{L} \geq 0.7$; this to ensure stable crack growth. Although unexpected considering the unstable crack growth for the double cantilever beam tests, preliminary experiments have shown that stable crack propagation is indeed achieved using this method for the material under study. As preliminary tests showed the expected behaviour without inducing a pre-crack, contrary to the DCB tests, no pre-crack is considered here.

Table 5 shows an overview of the four specimens illustrated in this manuscript. As can be seen, two different geometries are considered, to illustrate the effect of the geometry on the stable crack-growth and the results.

Table 5 Dimensions of the used ENF-specimens

\begin{tabular}{cccc}
\hline Specimen & $\begin{array}{c}\text { Width } \\
{[\mathrm{mm}]}\end{array}$ & $\begin{array}{c}\text { Half span L } \\
{[\mathrm{mm}]}\end{array}$ & $\begin{array}{c}\text { Crack length } \mathrm{a}_{0} \\
{[\mathrm{~mm}]}\end{array}$ \\
CET5 & 11.4 & 72.5 & 55 \\
\hline
\end{tabular}




\begin{tabular}{lccc}
\hline CET6 & 11.5 & 72.5 & 55 \\
CET7 & 16.1 & 100.0 & 70 \\
CET8 & 16.1 & 100.0 & 70 \\
\hline
\end{tabular}

Figure 12 shows the corresponding force-displacement curves of the ENF experiments, conducted at a speed of $0.5 \mathrm{~mm} / \mathrm{min}$, except for CET8, which was tested at $1 \mathrm{~mm} / \mathrm{min}$ to assess the influence of testing speed. For comparison purposes, all values have been normalized to a width of $20 \mathrm{~mm}$. These results were also found for other specimens, not illustrated here.

Force as function of the displacement for the Mode-II End Notch Flexure experiments

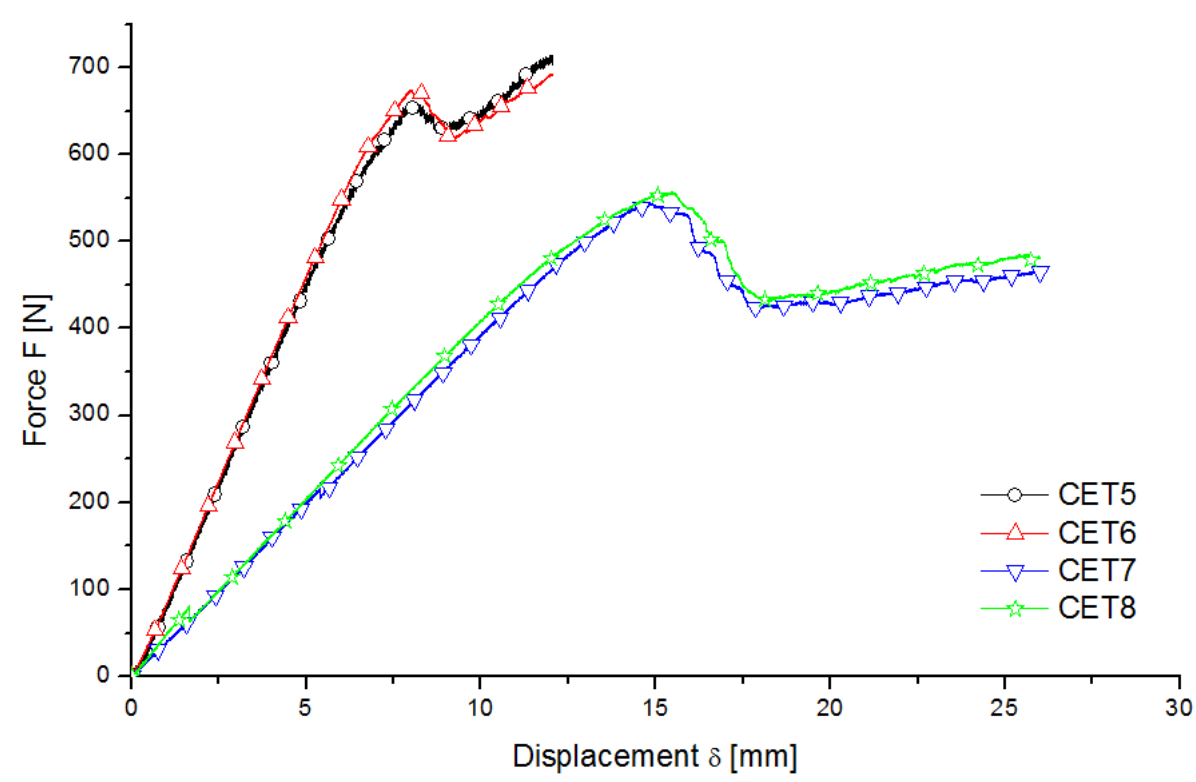

Figure 12 Force-displacement curve for the ENF tests

Several remarks can be made with respect to these results. First, it should be noted that the expected shape is present. The force increases until the crack initiates and propagates, resulting in a decrease in force. Once the crack has reached the centre of the specimen (or a little further) the force increases again, but with a different slope. The influence of the geometry is also clear. The larger specimens show a significantly larger stage of crack propagation, which will facilitate the determination of $\mathrm{G}_{\text {IIC }}$. Finally, the reproducibility of the results for the same geometry is very high (better than for the Mode I DCB tests), which was also confirmed by other experiments, not shown in this manuscript. The testing speed does not seem to have any influence, based on the forcedisplacement curve.

To derive $\mathrm{G}_{\text {IIC }}$ the following procedure is followed. From the force-displacement curve, the compliance $C(=\delta / F)$ is calculated and $C_{0}$ is determined from the linear part of this curve. Next, the flexural stiffness $E_{\mathrm{f}}$ is calculated:

$$
E_{f}=\frac{3 a_{0}^{3}+2 L^{3}}{8 b h^{3}}\left(C_{0}-\frac{3 L}{10 G_{13} b h}\right)^{-1}
$$

With $b=$ width of the specimen [m]

$\mathrm{h}=$ half the height of the specimen [m]

$\mathrm{a}_{0}=$ initial length of the delamination [m]

$\mathrm{L}=$ half the span $[\mathrm{m}]$ 
$\mathrm{C}_{0}=$ compliance of the linear part of the force-displacement curve $[\mathrm{m} / \mathrm{N}]$

$\mathrm{G}_{13}=$ shear modulus of the material $[\mathrm{Pa}]$

The fact that $G_{13}$ is necessary for this method is sometimes a problem, but for the material under study, the $\mathrm{G}_{13}$ value is accurately determined by meso-scale modelling [14] and is equal to $3048 \mathrm{MPa}$.

Equation 4 already takes the stress concentration around the tip and bending of the specimen into account, but it does not yet consider material degradation just behind the tip. The latter causes fibre-bridging, micro-cracks and other non-elastic effects which will of course affect the compliance and the actual delamination length. As such, a correction is necessary $[8,9]$ and the equivalent delamination length becomes:

$$
a_{e q}=\sqrt[3]{\frac{C_{c o r r}}{C_{0, \text { corr }}} a_{0}{ }^{3}+\frac{2}{3}\left(\frac{C_{c o r r}}{C_{0, \text { corr }}}-1\right) L^{3}}
$$

In this equation, $\mathrm{C}_{\mathrm{corr}}$ and $\mathrm{C}_{0, \text { corr }}$ are given by:

$$
C_{\text {corr }}=C-\frac{3 L}{10 G_{13 b h}} \text { and } C_{0, \text { corr }}=C_{0}-\frac{3 L}{10 G_{13 b h}}
$$

Finally, $\mathrm{G}_{\mathrm{IIC}}$ can be calculated as:

$$
G_{I I C}=\frac{9 F^{2} a_{e q}{ }^{2}}{16 b^{2} E_{f} h^{3}}
$$

Equation 7 is then plotted as a function of $\Delta \mathrm{a}_{\mathrm{eq}}=\mathrm{a}_{\mathrm{eq}}-\mathrm{a}_{\mathrm{eq}}{ }^{\text {mean }}$, with $\mathrm{a}_{\mathrm{eq}}{ }^{\text {mean }}$ the mean value of $\mathrm{a}_{\mathrm{eq}}$ where there was no crack growth [13]. The latter is, similar to Mode I, also referred to as the R-curve and normally shows a plateau; the value of this plateau is the

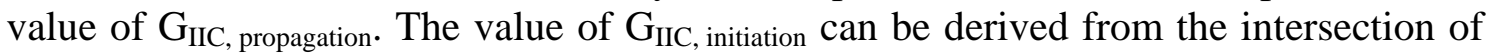
this curve with the vertical axis $\Delta \mathrm{a}_{\mathrm{eq}}=0$. Figure 13 shows the results corresponding with the experiments above. 
Mode II interlaminar fracture toughness

as function of the equivalent crack extension

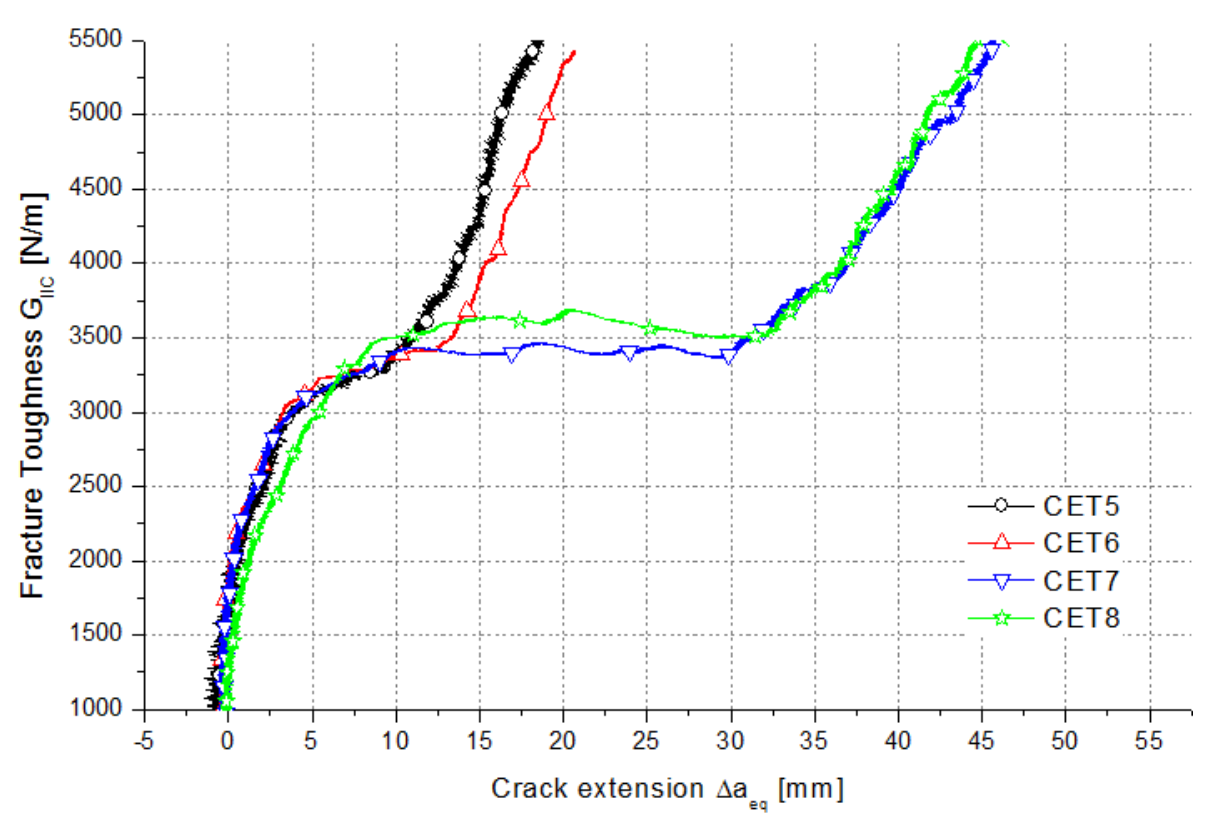

Figure $13 \mathrm{G}_{\mathrm{IIC}}$ as function of $\Delta \mathrm{a}_{\mathrm{eq}}$ for the ENF experiments.

First, it should be noted that the correspondence for initiation and stable crack growth is very high for specimens CET5 till 7. Also, the difference in geometry has a definite influence on the crack propagation, the plateau corresponding with the larger specimens is more pronounced, making it easier to determine the value of $\mathrm{G}_{\text {IIC, propagation. }}$ Nevertheless, if the scaling is adjusted only to the curves of CET5 and CET6, a sufficient flat part of the curve, containing a large number of data points (note: only one every 700 points is given a symbol in Figure 13) is visible. As such, values for $\mathrm{G}_{\mathrm{IIC}}$, propagation can also be derived for these experiments.

Given this high correspondence for these specimens, which was also verified for other samples, not mentioned here, the different behaviour of CET8 can only be caused by the testing speed, since all other variables are the same. A higher testing speed results in a

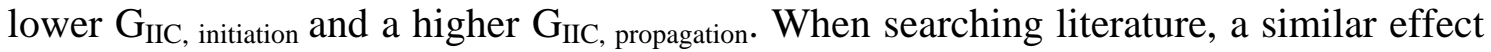
was found in [15] for the $\mathrm{G}_{\text {IIC, propagation }}$ of carbon reinforced PEEK, but Compston et al. did not see a loading rate effect for a glass vinyl-esther [16]. As is clear from a literature review by Cantwell et al. [17], different findings exist in literature on this matter and a more extensive study, purely focused on the effect of loading rate on the $\mathrm{G}_{\text {IIC, initiation and }}$

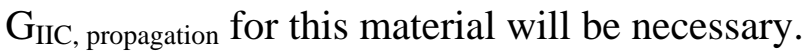

Table 6 gives an overview of the calculated values for the Mode II fracture toughness. For the average values, specimen CET8 is left out because of the apparent speed dependence. The values are significantly higher than in $[6,7]$, which reported values around $2500 \mathrm{~N} / \mathrm{m}$ for the 8-harness PEI. Of course, this might be caused both by the different matrix (PEI versus PPS) and the weave pattern.

Table 6 Summary of the derived values of $\mathrm{G}_{\text {IIC }}$

\begin{tabular}{ccc}
\hline Specimen & $\mathrm{G}_{\mathrm{IIC} \text {, initiation }}[\mathrm{N} / \mathrm{m}]$ & $\mathrm{G}_{\mathrm{IIC} \text {, propagation }}[\mathrm{N} / \mathrm{m}]$ \\
CET5 & 1725 & 3130 \\
CET6 & 1925 & 3337 \\
CET7 & 1750 & 3395 \\
\hline
\end{tabular}




\begin{tabular}{ccc}
\hline CET8 & 1250 & 3580 \\
Average & 1800 & 3287 \\
\hline
\end{tabular}

Similar to the Mode I assessment, a microscopic study was performed on a polished side of a ENF specimen. Here, it was verified that indeed a continuously stable crack propagation occurred, contrary to the DCB-tests. Occasionally, a meta-delamination occurred similar to the Mode I experiments, but since this study revealed no other relevant occurrences, it is not added to this manuscript.

\section{Conclusions}

This manuscript has studied the interlaminar fracture toughness behaviour of a 5harness carbon fabric reinforced thermoplastic under Mode I and Mode II loading conditions. To induce the mode I crack propagation, the Double Cantilever Beam (DCB) setup was considered. Because of the nature of the reinforcement, namely the 5harness fabric, no stable crack propagation was present, the crack propagated in sudden jumps. Hence, it was not possible to use the procedure of the ASTM D5528-01 Standard test method for Mode I interlaminar fracture toughness of unidirectional fiberreinforced polymer matrix composites', so a different procedure was used. Using an analytical model based on linear elastic fracture mechanics, a curve was plotted on the experimentally derived force-displacement curve. Two values for $\mathrm{G}_{\mathrm{IC}}$ were determined,

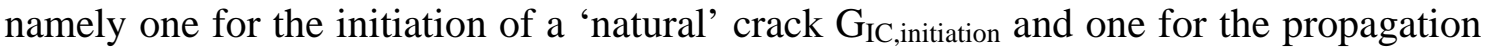

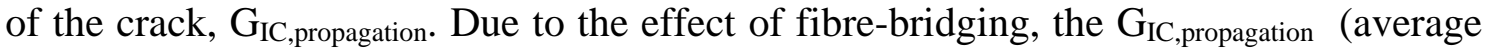

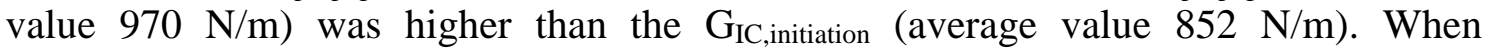
(partially) eliminating the fibre-bridging, the maximum peak forces were lower,

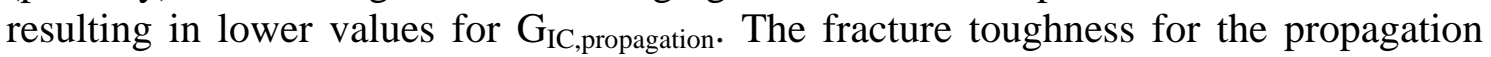
starting from the insert was not derived, since in real-life structures, such an insert would not be present. A microscopic study of the crack growth revealed that the jumps in the force-displacement curve were due to the specific 5-harness geometry of the reinforcement. The crack always started and ended either just before or just after a weft $\left(90^{\circ}\right)$ bundle and no stable propagation was present when the crack tip was between two neighbouring warp $\left(0^{\circ}\right)$ bundles, seen from the side.

In order to induce mode II crack propagation, the End Notch Flexure test (ENF) was used. Contrary to the DCB experiments, the crack showed stable propagation. Using the Compliance-Based Beam Method, A value of $1800 \mathrm{~N} / \mathrm{m}$ was found for $\mathrm{G}_{\text {IIC, initiation and, }}$ similar to mode I, a higher value of $3287 \mathrm{~N} / \mathrm{m}$ for $\mathrm{G}_{\text {IIC, propagation. Apparently, a higher }}$ loading rate causes a lower value for initiation and a higher value for propagation, although further research is necessary to validate this last result.

\section{Acknowledgements}

The authors are highly indebted to the Fund of Scientific Research - Flanders (F.W.O.) for sponsoring this research and to Ten Cate Advanced Composites for supplying the material. Also special thanks to L. Thijs, H. Opgenhaffen and L. Vanden Broecke for their contributions to this work.

\section{References}

[1] Sela, N and Ishai, O. Interlaminar fracture-toughness and toughening of laminated composite materials - A review. COMPOSITES 20 (5) Pages: 423-435 (1989)

[2] Martin, RH. Interlaminar fracture characterization. FRACTURE OF COMPOSITES Book Series: KEY ENGINEERING MATERIALS 120 Pages: 329-345 (1996) 
[3] Baley, C, Davies, P, Grohens, Y and Dolto, G. Application of Interlaminar Tests to Marine Composites. A Literature Review. APPLIED COMPOSITE MATERIALS 11 (2) Pages: 99-126 (2004)

[4] de Morais, AB, Rebelo, CC, de Castro, PMST, Marques, AT and Davies, P. Interlaminar fracture studies in Portugal: past, present and future. FATIGUE \& FRACTURE OF ENGINEERING MATERIALS \& STRUCTURES 27 (9) Pages: 767-773 (2004)

[5] Fracasso, R., Rink, M, Pavan, A and Frassine, R. The effects of strain-rate and temperature on the interlaminar fracture toughness of interleaved PEEK/CF composites. COMPOSITES SCIENCE AND TECHNOLOGY 61(1) Pages: 57-63 (2001) .

[6] Zenasni, R.,Bachir, A. S.,Argueelles, A.,Castrillo, M. A. and Vina, J. Fracture Characterization of Woven Fabric Reinforced Thermoplastic Composites. JOURNAL OF ENGINEERING MATERIALS AND TECHNOLOGY-TRANSACTIONS OF THE ASME 129 (2) Pages: 190-193 (2007)

[7] Zenasni, R and Saad, BA. Moisture effect on the interlaminar resistance of woven fabric thermoplastic composite. JOURNAL OF THERMOPLASTIC COMPOSITE MATERIALS 19 (6) Pages: 715-729 (2006)

[8] Wen-Xue Wang, Miko Nakatab, Yoshihiro Takao and Terutake Matsubara . Experimental investigation on test methods for mode II interlaminar fracture testing of carbon fiber reinforced composites. Composites: Part A 40 (2009) 1447-1455.

[9] Srinivasan Sridharan. Delamination behaviour of composites. Cambridge: Woodhead Publishing Limited, Boca Raton: CRC Press LLC. (2008).

[10] De Baere I., Van Paepegem W., Degrieck J., Sol H., Van Hemelrijck D. and Petreli A., Comparison of different identification techniques for measurement of quasi-zero Poisson's ratio of fabric reinforced laminates. Composites A 38 (9) pp. 2047-2054. (2007)

[11] Frassine R, Rink M and Pavan A. Viscoelastic effects on the interlaminar fracture behaviour of thermoplastic matrix composites .2. Rate and temperature dependence in unidirectional peek/carbon-fibre laminate. COMPOSITES SCIENCE AND TECHNOLOGY 56 (11) Pages: 1253-1260 (1996)

[12] Turon, A. Camanho P.P., Costa J. And Renart J. Accurate simulation of delamination growth under mixed-mode loading using cohesive elements: definition of interlaminar strengths and elastic stiffness. Composite Structures 92 (8), pp 1857-1864 (2010)

[13] Arrese A., Carbajal N., Vargas G. and Mujika F. A new method for determining mode II Rcurve by the End-Notched Flexure test. Engineering Fracture Mechanics Volume 77, Issue 1, January 2010, Pages 51-70

[14] Daggumati S., Van Paepegem, W., Degrieck, J. Xu J., Lomov S.V. and Verpoest I. Local damage in a 5 - harness satin weave composite under static tension: part II - meso - FE modeling. Composites Science and Technology 70 (13) Pages: 1934-1941 (2010)

[15] Berger, L and Cantwell, WJ. Temperature and loading rate effects in the mode II interlaminar fracture behavior of carbon fiber reinforced PEEK. POLYMER COMPOSITES 22 (2) pp: 271281 (2001).

[16] Compston, P ,Jar, PYB, Burchill, PJ and Takahashi, K. The effect of matrix toughness and loading rate on the mode-II interlaminar fracture toughness of glass-fibre/vinyl-ester composites. COMPOSITES SCIENCE AND TECHNOLOGY 61 (2) pp: 321-333 (2001).

[17] W.J. Cantwell and M. Blyton, Influence of loading rate on the interlaminar fracture properties of high performance composites — a review. Appl. Mech. Rev., 526 (1999), pp. 199-212. 